\title{
CONGREGATION OF ROUGH-LEGGED HAWKS BUTEO LAGOPUS
}

BOB GODWIN, 1125 4th St. East, Saskatoon SK. S7H 1K7

On 27 March 2014, I was driving south from Rosetown and saw a larger number of Rough-legged Hawks than I have ever seen at one time before - 76 between Rosetown and Kyle. It seemed rather unusual to me, although I have observed reasonably high numbers before. When I say I saw 76, not all were identified individually as Rough-legged Hawks, as they were on posts removed from the highway and a spotting scope would have been required to study them. It would have taken me hours to stop and check each one; as it was, it slowed up my trip considerably. However, I did look at approximately 15 of them well enough for identification, and every one was a Rough-legged Hawk.

A particular concentration occurred in the area north from Elrose, where I observed 28 individual Rough-legged Hawks in a distance of six to seven kilometers. In this area, there is a high voltage transmission line, where the supports for the lines consist of two large vertical wooden poles joined near the top by a large wooden cross pole. Often there was more than one hawk on one of these support systems; in one instance there were four hawks on a single structure. Twenty-six hawks were in a 17 pole stretch, which, based on an average pole spacing of $193 \mathrm{~m}$ in this region as measured from Google Earth imagery, was estimated to be $3.1 \mathrm{~km}$.

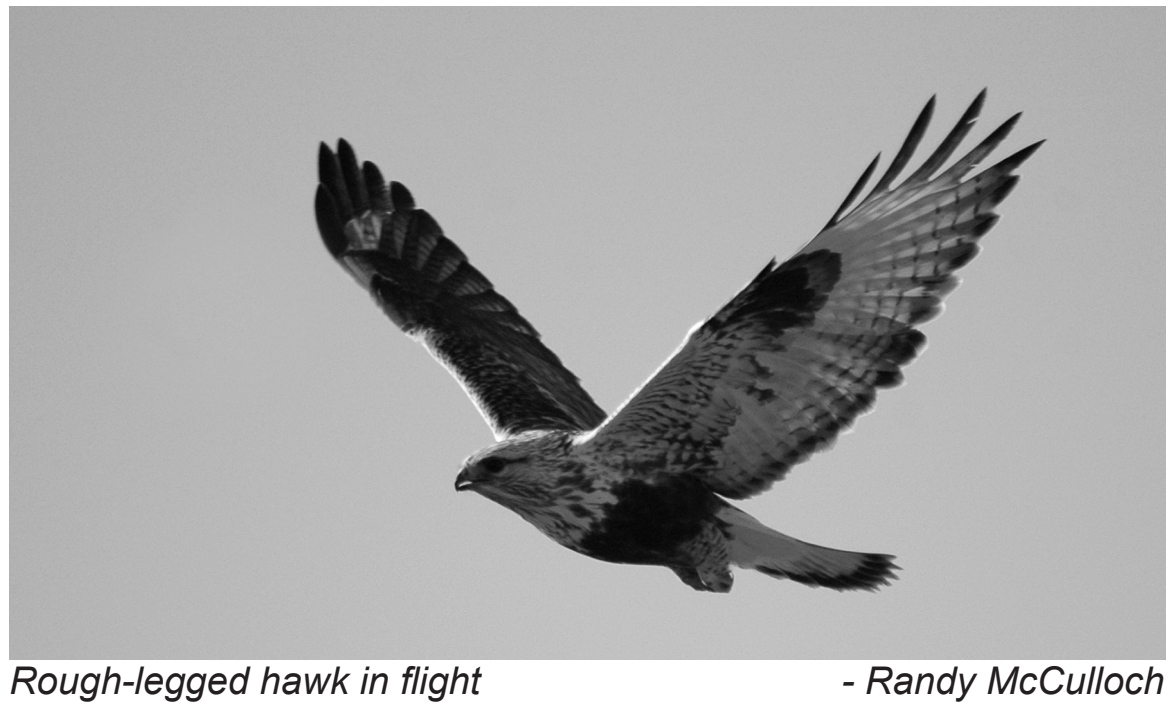




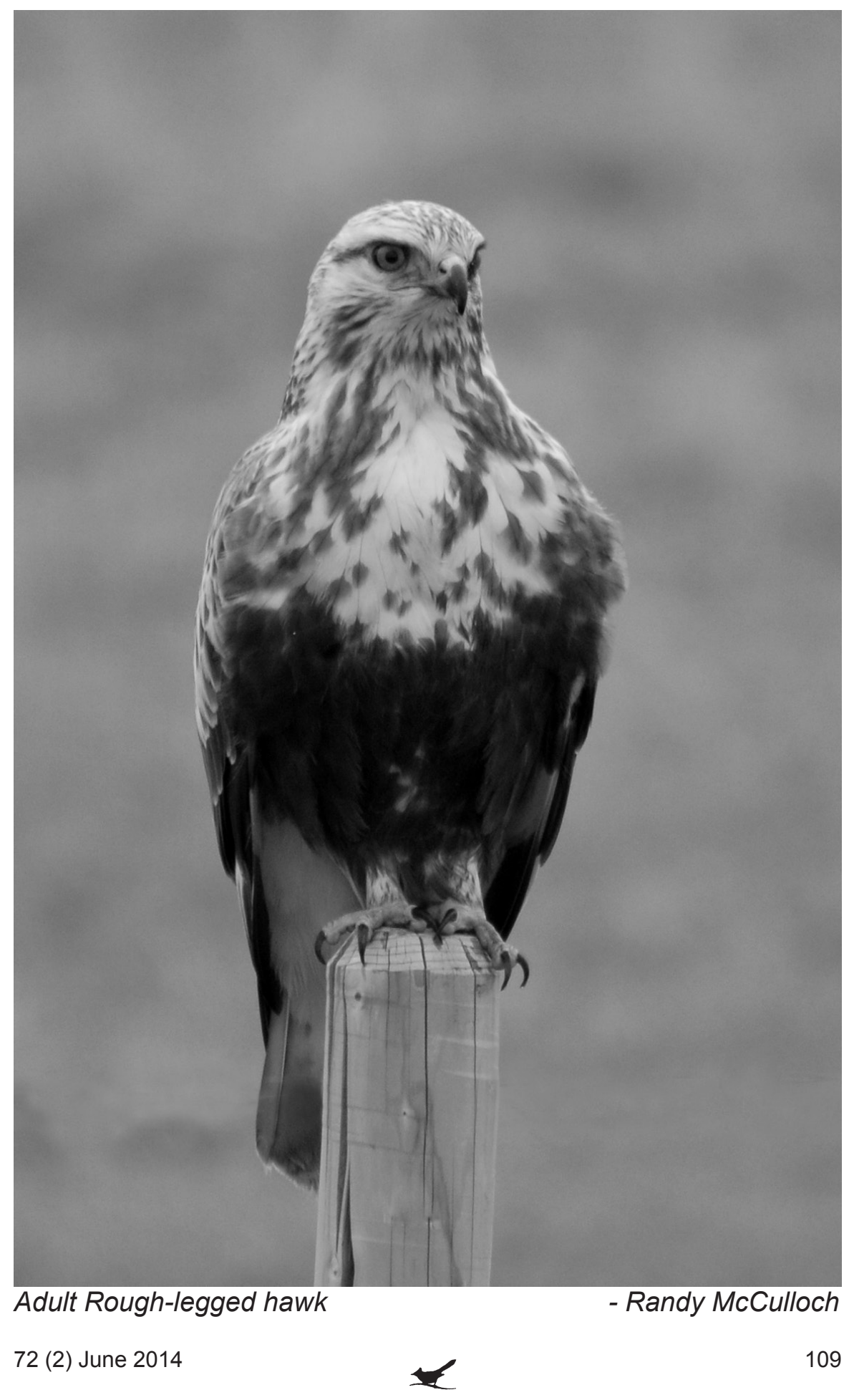

